\title{
BMJ Open Investigating the organisational impacts of quality improvement: a protocol for a realist evaluation of improvement approaches drawing on the Resource Based View of the Firm
}

\author{
Christopher R Burton, ${ }^{1}$ Jo Rycroft Malone, ${ }^{1}$ Glenn Robert, ${ }^{2}$ Alan Willson, ${ }^{3}$ \\ Angela Hopkins ${ }^{4}$
}

To cite: Burton CR, Rycroft Malone J, Robert G, et al. Investigating the organisational impacts of quality improvement: a protocol for a realist evaluation of improvement approaches drawing on the Resource Based View of the Firm. BMJ Open 2014;4: e005650. doi:10.1136/ bmjopen-2014-005650

- Prepublication history and for this paper is available online. To view these files please visit the journal online (http://dx.doi.org/10.1136/ bmjopen-2014-005650).

Received 7 May 2014 Revised 4 July 2014 Accepted 11 July 2014

CrossMark

For numbered affiliations see end of article.

Correspondence to Dr Christopher R Burton; c.burton@bangor.ac.uk

\section{ABSTRACT}

Introduction: Little is understood about the role of quality improvement in enabling health organisations to survive and thrive in the contemporary context of financial and economic challenges. We will draw on the theoretical foundations of the 'Resource Based View of the Firm' (RBV) to develop insights into why health organisations engage in improvement work, how impacts are conceptualised, and 'what works' in delivering these impacts. Specifically, RBV theorises that the mix and use of resources across different organisations may explain differences in performance. Whether improvement work influences these resources is unclear.

Methods and analysis: Case study research will be conducted across health organisations participating in four approaches to improvement, including: a national improvement programme; a multiorganisational partnership around implementation; an organisational strategy for quality improvement; and a coproduction project designed to enhance the experience of a clinical service from the perspective of patients. Data will comprise in-depth interviews with key informants, observation of key events and documents; analysed within and then across cases. Adopting a realist perspective, the core tenets of RBV will be evaluated as a programme theory, focusing on the interplay between organisational conditions and behavioural or resource responses that are reported through engagement in improvement.

Ethics and dissemination: The study has been approved by Bangor University Ethics Committee. The investigation will not judge the relative merits of different approaches to healthcare quality improvement. Rather, we will develop unique insights into the organisational consequences, and dependencies of quality improvement, providing an opportunity to add to the explanatory potential of RBV in this and other contexts. In addition to scientific and lay reports of the study findings, research outputs will include a framework for constructing the economic impacts of quality improvement and practical guidance for health service managers that maximises the impacts of investment in quality improvement.

\section{Strengths and limitations of this study}

- A realist evaluation that draws on theory from strategic management, and the Resource Based View of the Firm in particular, to develop explanatory evidence of the organisational consequences of quality improvement.

- Findings will have potential to inform guidance for health service managers about how they can capitalise on the impacts of quality improvement, and shape business cases that argue for continuing investment in improvement initiatives.

- Case study research draws on one theoretical perspective, requiring attention to be paid to other explanations that emerge directly from the data.

\section{INTRODUCTION}

Drawing on the Resource Based View of the Firm (RBV), ${ }^{1}$ the study will investigate how participation in quality improvement brings competitive advantage to healthcare organisations within the political and other contexts in which they operate. This will require attention to be paid to what resources have value across the different forms of organisational resources that are involved in improvement work, and how these resources are used to maximum benefit within the organisation.

RBV theorises organisations comprise a mix of tangible and intangible resources, including physical, human and organisational capital. ${ }^{1}$ Differences in these resources explain variation in organisational performance. Where these resources have value, rarity, are difficult to imitate, and are nonsubstitutable, characterised as VRIN, then organisations have competitive advantage relative to others. ${ }^{2}$ Maximising performance depends on both an organisation's capability 
to recognise and exploit these resources, ${ }^{3}$ and the ability to re-engineer new resources in a changing strategic environment may be key to sustaining performance. ${ }^{4} 5$ These abilities typically refer to consolidating, replicating or extending resources across an organisation; learning; and the creative integration of resources. Empirical evaluations of RBV have provided mixed evidence of construct validity, ${ }^{6}$ leading to calls for further theoretical refinement. ${ }^{7}$ Concepts within RBV that require further investigation within the context of healthcare improvement include what counts as a resource, how value is determined and what counts as competitive advantage. ${ }^{8}$

RBV has principally been used to examine performance within the private sector, usually in terms of a firm's financial performance, or market share, relative to its competitors. However, competition can operate in other aspects of organisational performance in quasimarket contexts, including patient choice ${ }^{9}$; quality performance ${ }^{10}$; efficiency and value for money ${ }^{11}$; the impacts of reputation on workforce issues, ${ }^{12}{ }^{13}$ and reputation through public reporting. ${ }^{14}$ Quality improvement is therefore strategic to healthcare organisations, seeking to enhance aspects of service organisation and delivery for outcomes that have value for patients, staff and organisations. In this way, it has the potential to increase the range and value of different resources within an organisation, including improvement capability and learning and strategic potential.

RBV focuses primarily on the strengths within an organisation to manage uncertainty, rather than capitalising on the external environment. ${ }^{15}$ This will depend on the scope to invest in improvement work, ${ }^{16}$ and organisational slack, or free resources, to support learning and innovation. ${ }^{13}$ Strengths which have strategic value will include knowledge of, and learning about improvement work located within the organisation. Attention to the internal environment of organisation can be linked through theories of Dynamic Capability (eg, sensing, seizing and responding to opportunity ${ }^{17}$ and Absorptive Capacity (eg, external exploration and internal exploitation ${ }^{18}$ ) to environmental factors that shape performance.

Across different theoretical and practical traditions, improvement encompasses mechanisms that operate at individual, team and organisational levels. ${ }^{19}$ There is a focus on the utilisation of evidence, although the field has expanded to include different views about what counts as evidence, to include experiential, local and other forms of knowledge. ${ }^{20}$ Attention is also being paid to the ways in which evidence can be developed that enhance its implementability. ${ }^{21}{ }^{22}$ Improvement work relies on a range of mechanisms of action (eg, knowledge and skills, motivation and cultural change) operating at different and multiple organisational layers. From the perspective of RBV, these mechanisms may build or reposition resources, and, focusing on strengths, provide a focus for the development of organisational strategy. ${ }^{7}$ The mechanisms of action will be related to (often multiple) theories underpinning improvement interventions, drawn from psychological, sociological and other disciplines.

Broadly, the domain of improvement research is quality, although the improvement efforts may focus on different domains of healthcare, such as system reliability, patient safety, and the clinical effectiveness of healthcare services. Closing the gap between evidence and practice, reliable and unreliable performance or from low to high quality care represents a behaviour change associated with cognitive work, and learning at both the level of individual clinicians, teams and from an organisational perspective. This cognitive work relates to both the clinical or service challenge at the focus of the improvement work (eg, the safety of drug administration), and the theoretical and practical aspects of improvement work more generally. Inevitably, the success of improvement will vary across organisational and programme contexts, although the combinations of pre-requisites for success are poorly understood. In addition to incentives embedded within individual and organisational performance review, ${ }^{23}$ work to ensure that patients receive a safe, reliable and evidence-based care experience reflects an ethical and moral dimension to quality improvement, with personal consequences for individual healthcare professionals. ${ }^{24}$

Despite variation in the national political frameworks underpinning the structure of individual nations' health services, there are some core influences on quality improvement. In the UK for example, attempts to control public expenditure on health are challenged by changing population characteristics; increasing demand for more complex and long-term healthcare; and increasing costs associated with technological and pharmaceutical innovation. Moreover, high expectations of healthcare held by an increasingly knowledgeable public are coupled with stringent financial and clinical performance standards demanded from government and service commissioners. Performance against standards is open to ever increasing transparency and scrutiny, and high-profile crises in service quality have challenged the reputation of the National Health Service celebrated in the 2012 Olympic Opening Ceremony. Consequently there is considerable interest in developing the science and practice of improvement in healthcare. This study will directly contribute to this agenda by evaluating the explanatory capacity of RBV in this context.

\section{METHODS AND ANALYSIS}

To develop insights into the processes and impacts of implementing quality improvement, a realist evaluation will be conducted across: a national improvement programme; a multiorganisational partnership around implementation; an organisational strategy for quality improvement; and a coproduction project designed to enhance the experience of a clinical service from the 
perspective of patients. The study will start in September 2015 and run for 24 months. The study objectives are:

1. To investigate how health organisations perceive the relationship between improvement work and organisational strategy;

2. To explore which, and how different physical, human and organisational resources contribute to an understanding of 'what works' in improvement work;

3. To explore how organisational participation in improvement approaches can change an organisation's profile of physical, human and organisational resources;

4. To explore how changing resources can be used by health organisations to deliver their organisational strategy.

\section{Theoretical framework}

The study theoretical framework is summarised in figure 1 . RBV potentially provides a bridge between an organisation's internal and external environments, by explaining how the positioning and renewal of VRIN resources and capabilities can enable performance to be sustained.

The organisation delivery of quality improvement programmes can vary, spanning different organisational units at different times, with antecedents and consequences at different levels within participating organisations. Soft systems methodology provides a consistent epistemological approach for analysing open systems, which may combine multiple cognitive, social and cultural perspectives, ${ }^{25}$ within which improvement programmes operate. As such, it is eminently suited to the investigation of the contexts of improvement which may similarly be described as complex and messy. ${ }^{26}$ In this study, the configuration of people, interventions and resources around a quality improvement programme will be characterised as a soft, human adaptive system which is open to differing interpretations about purpose, value and impact. ${ }^{27}$ This characterisation will underpin the ways in which cases are conceptualised within the different approaches to improvement outlined above.

\section{Realist evaluation}

Within this study, the purpose of realist evaluation is to develop an explanatory account or programme theory about 'what works' about quality improvement, and in what contexts. Explanatory accounts comprise configurations of context (the contingencies on which programme changes are dependent), mechanism (the changes that are brought about through a programme) and outcomes (programme impacts). These configurations are developed iteratively through data collection, theorising and stakeholder engagement. Moreover, the evaluator is required to look 'behind' a programme's operations to identify explanatory accounts of its impact. This presents a significant challenge as mechanisms of change may be more or less obvious within the empirical world that can be experienced through observation. $^{28} 29$ The analytical purpose is to produce propositions, or demi-regularities, across context-mechanismoutcome configurations which have maximum explanatory potential. These demi-regularities provide the foundation for the development of more abstract, mid-range theoretical interpretation that can enhance the transferability of findings.

Typically, realist researchers rely on a deep interpretation of rich data to develop theoretical explanations, which are then refined through testing in a range of different contextual conditions. As an emerging methodology within health services research, the lack of any rigid guidance on realist evaluation design provides opportunities for creativity to drive the explanatory depth and richness of programme theory. This creativity may be drawn from a multidisciplinary array of theoretical perspectives informing the analysis, or the novel use of

Figure 1 Study conceptual framework.

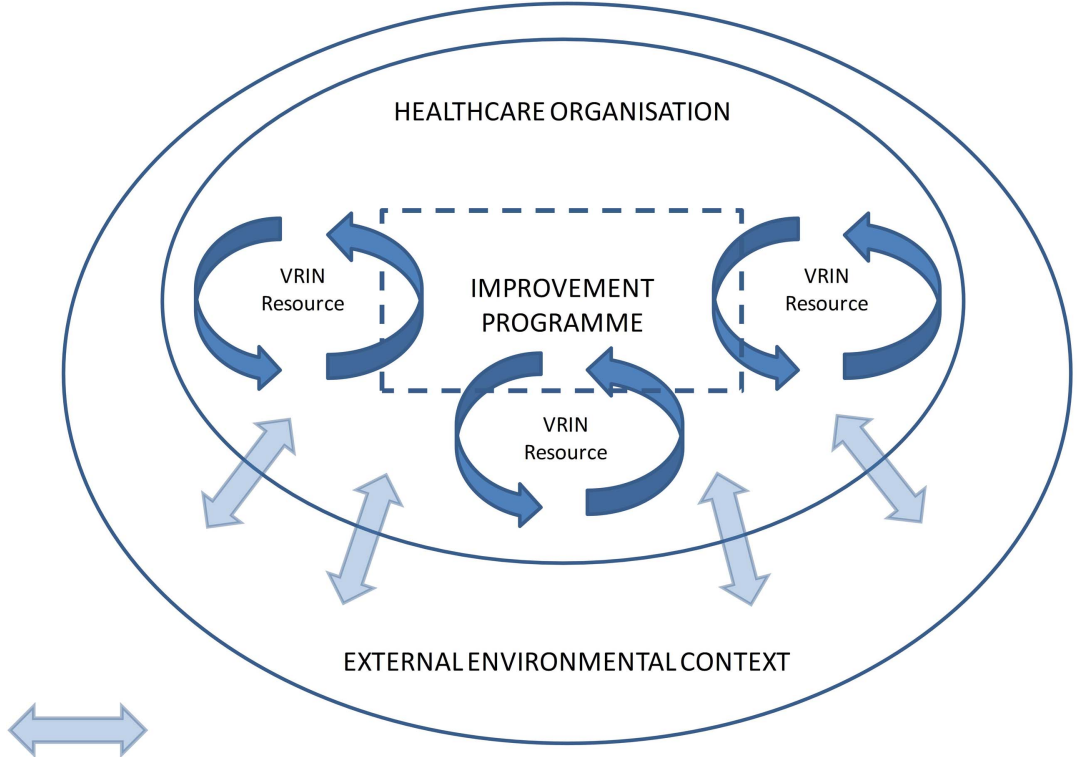

Denotes competitive advantage within market (e.g. value for money, contestability, reputation, quality, patient choice etc.) 
theories such as RBV. As a mid-range theory, RBV should provide a sufficient level of abstraction to enable generalisations across programmes to be made, or from a realist perspective, explanations of demi-regularities to be made.

Case study methods will guide the collection and analysis of multiple sources of data within and across the four approaches to improvement. ${ }^{30}$ As with Ovretveit and Klazinga, ${ }^{31}$ a case will constitute a discrete improvement initiative, defined from a soft systems perspective by factors such as people and roles; changes planned and observed; policy and professional contexts; leadership and project management; and information and financial flows. Sampling of cases will be based on a replication and maximum variation argument; that is, each case will be selected so that they (1) predict similar results or (2) provide contrasting results but for predictable reasons. In this way, a set of propositions or hypotheses representative of RBV could be tested over the cases. Attention will be paid in sampling to include concurrent improvement work in one organisation; and different types of improvement projects. The anticipated cases are listed below, and data will comprise interviews with project participants and stakeholders, observational data, project records and reports. Analysis will include secondary analysis of data sets created as part of internal or other external evaluation where permissible. The analytical task is to test the credibility of explanatory propositions within multiple types of data, driven, but not constrained by an overarching programme theory (RBV).

Yin describes a case in terms of the real-world setting in which the focus of study occurs, although the boundaries of the phenomenon and context may be blurred. Reflecting the complex nature of improvement programmes, the importance of context within improvement research in explaining differential effects, or a lack of generalisability across health organisations, has been emphasised. A significant challenge is the clarification of context, which may incorporate political, organisational and geographical factors which influence in different ways for different aspects of improvement work. ${ }^{32}$ Improvement practice is often influenced by Lewin's ${ }^{33}$ ideas around organisational factors as a 'backdrop' to an improvement programme, and which poses constraining and enabling forces that enable an improvement programme to work or not. These factors may be described in terms of domains, such as strategic, cultural, technical and structural; or metaphors such as receptivity. Although receptivity describes the product of context rather than the contextual features themselves, it is typical of a reductionist approach which summarises context as conducive or not, and is consistent with attempts to achieve experimental control, some form of 'subgroup analysis', in improvement research.

Our methodological perspective, and specifically the integration of Bhaskhar's critical realism and social sciences, ${ }^{34}$ provides an opportunity to adopt a more nuanced approach to uncovering the contextual conditions that are associated with successful improvement. Realist evaluation is concerned with the evaluation of complex programmes operating in open, rather than closed, social systems which have the potential to produce change. These social systems can be characterised as both structure and agency, emphasising the dynamic nature of context in influencing how programme participants respond to participation. In this sense, explanations of 'what works' are contingent on context and should focus on the underlying potential of staff and organisations that is, or can be, 'released' through improvement. Context is more than a mix of factors operating behind an improvement programme, and its investigation must be at the interface of the changes brought about by the programmes being evaluated, rather than interpreted as the settings in which they are being delivered.

Four cases have been purposively selected as the focus of investigation, each representing a particular approach to supporting healthcare improvement. These are:

1. The Collaboration for Leadership in Applied Health Research in Care (CLAHRC) programme of partnerships between health organisations and University research departments to accelerate research and implementation within geographical regions in National Health Service (NHS) England

2. One healthcare organisation providing a mix of primary care, hospital and community-based services for a geographical region within the UK,

3. One national improvement programme designed to support improvement across health organisations, and

4. A coproduction project designed to enhance the experience of a clinical service from the perspective of patients.

The UK has seen a proliferation of improvement programmes which draw on organisational collaboration as a mechanism to increase health research capacity, knowledge mobilisation and quality improvement. Examples include the Academic Health Science Networks and CLAHRCs. ${ }^{35}$ This study will draw on a considerable data set generated as part of an on-going evaluation of the CLAHRC programme in NHS England ${ }^{36}$ as Case 1. Unilateral organisational approaches to improvement, including the decision to participate in broader collaborative improvement programmes, will be explored in one health organisation as Case 2. To determine how collaborative improvement programmes have the potential to scale-up improvement work and to share learning and expertise, a national improvement programme in the UK will be sampled as Case 3, focusing on the interface between the programme and participating health organisations. While many improvement interventions have been subject to investigation, patient and public involvement (PPI) has received less attention outside of a research context. Research funded through the UK National Institute for Health Research is expected to demonstrate the depth of PPI across research 
management, design, data collection and analysis, and dissemination. There is increasing attention on the role of PPI in improvement. ${ }^{37}$ RBV may be relevant to PPI in improvement, for example in highlighting the role of potential knowledge resources relating to service user preference, expectations and feedback on organisational performance. In addition, the integration of PPI within improvement work provides an interesting opportunity to investigate the role of potentially quite different mechanisms of action (eg, emotional mechanisms) which may contribute to success. Originating in the design sciences, we will draw on Experience-based Co-Design (EBCD) as a systematic approach to including patient perspectives in quality improvement. ${ }^{24}$ Case 4 will comprise a healthcare organisation that has adopted $\mathrm{EBCD}$ as an approach to improvement.

Other than for Case 1, each case will be asked to nominate an internal facilitator who will take responsibility for enabling access to sites and participants; advising on specific research governance processes; and providing a bridge for communication between the study and relevant people within the organisation, and for dissemination activities. As a single organisational entity, the focus of investigation in Case 2 will be the strategic and operational work in addressing the organisation's improvement needs. Within Cases 3 and 4, data collection and analysis will focus on embedded units that constitute a sample of the legally constituted health organisations participating in these programmes. For example, clinical services participating in EBCD within the organisation will constitute embedded units for Case 4 .

\section{Data collection}

Within each case and embedded unit, data collection will be undertaken by the lead author and guided, but not constrained by the overviews of systems generated through the soft systems analyses. Interviews with key informants and documents data will form the sources of research data. Interviews will be fully transcribed; transcripts and included documents will be managed using Atlas $\mathrm{Ti}$ software which supports the organising and coding of different forms of qualitative data.

\section{Interviews}

Semistructured interviews with key informants at multiple levels within and across each case and embedded, facilitated by a nominated internal facilitator within each participating organisation. Facilitators will keep a record of the numbers of informants approached, and the number of refusals. A bespoke sampling framework for interviews will be determined separately for each case, drawing on the soft systems analysis described earlier. On the basis of this work, theoretical sampling will be used to identify interview participants drawn from the key components of the organisation's improvement work. This will ensure that there is maximum potential to identify improvement resources and impacts at different organisational levels, and to understand how these are managed within the organisation. A criterion sampling will be used to ensure the inclusion of a variety of participants with criteria being developed to include different professional backgrounds and experience of improvement work.

Interviews will focus on the perceptions of participants about the interfaces between improvement programmes, organisational context and the strategic environment in which health organisations are operating. Key themes will draw on RBV, paying attention to participants' views of:

- The design of the improvement programme and its strategic fit with other organisational activities;

- Programme content, including the core components, activities and mechanisms of change;

- Programme impacts for staff, patients, organisations and other stakeholders;

- The resources and capabilities used or developed within the improvement programme;

- Personal and organisational learning around the improvement programme and improvement generally; and

- The sustainability of improvement, and on-going utilisation of improvement resources.

The interview guide will be piloted in three interviews with colleagues with relevant experience of quality improvement, but in different organisational contexts, prior to formal data collection. It is estimated that interviews will average about $45 \mathrm{~min}$ in length, although the actual length of interviews will be recorded and reported.

To unpick the role of context where changes in participants' own or others' thinking or action are highlighted, questions which seek to clarify the contingencies of these changes will be used. The inclusion of open-ended questions will ensure that interviews are not constrained to an RBV perspective. Participants will be able to choose to be interviewed either face-to-face or by telephone. The number of interviews conducted will be determined on a case-by-case basis, but is likely to be up to 20 in each embedded unit. This reflects our experience of achieving data saturation in a similar study conducted across three organisational cases. ${ }^{39}$ Interviews will be digitally recorded with participants' consent. An Interview Summary form will record the mode and setting of interviews, and the presence of any non-participants. Reflexivity will be kept under scrutiny by the interviewer through reflection after each interview utilising a structured reflection which has been developed and refined in previous studies. ${ }^{40}$ These reflections will form a focus for on-going review of data collection by the research team.

\section{Observation}

Guided by the internal facilitator for each case, nonparticipant observation of a sample of quality improvement meetings and activities will be undertaken, and 
written up as field notes. The selection of which meetings and activities to be observed will be mapped against the research objectives to identify appropriate sampling, for example from project to organisational strategy within each embedded unit or case. These observations will focus on interactions and be informed by an observation framework developed from Spradley's ${ }^{41}$ nine dimensions of observation, including space, actors, activities, objects, acts, events, time goals and feelings.

\section{Additional data}

Additional forms of data that can assist in interpretation and explanation building will be also collected. These will include documentary material relevant to the organisation and delivery of improvement work within embedded units, and organisational strategy. Improvement related documents may be in the form of reports or publications related to specific projects, or those that form the institutional record of improvement strategy and its implementation, such as policies, minutes of meetings, and other artefacts of the reporting structure.

\section{Data analysis}

The analysis will be managed using Atlas-Ti computer software. In brief, RBV will provide a foundation from which to build, test and refine multiple hypotheses which describe the interplay between improvement activity, the range and value of related organisational resources, and associated organisational impacts. The analysis and interpretation of data will focus on the full range of resources that are in play across the cases, how impacts are conceptualised, and 'what works' in delivering these impacts. Consequently, a directed qualitative content analytical approach will be used, ${ }^{42}$ where deductive categories, representing key concepts from $\mathrm{RBV}$, will be used to code and integrate data across interviews. ${ }^{43}$ The goal of directed content analysis is to evaluate the transferability of a theoretical framework or theory, and to extend its application in different empirical contexts. From an interpretive perspective, there is a danger that such an analysis may be restrictive in generating different or challenging insights into a given phenomenon. However, attention can be paid to data that cannot be categorised, but which are relevant to the research aims, by the use of new codes which describe these data. Coding will be undertaken by the lead author. Data tables which enable on-going review of code specification, within case and cross case variation will be reviewed by the study team during the analysis. The final coding frame will be included in study outputs where possible.

In this study, the analytical task will be to apply conceptually and theoretically RBV as a potential explanatory framework for improvement within healthcare. This will be addressed in two ways. Initially, the analysis will seek to extend understanding of the concepts relevant to RBV within the cases through, for example, investigating their meaning and inter-relationships within the context of improvement work through the perceptions of study participants. Initial operational definitions for codes will be established from the extant literature on RBV, the dimensions of which will be refined across the analysis in new organisational contexts and improvement challenges.

The second task will address the realist nature of this investigation, by seeking contingent explanations of the relationships between the existing codes around improvement work and the delivery of organisational strategy, in the form of context, mechanism, outcome configurations (CMOCs). As these CMOCs will form a bridge between the experience and interpretations of study participants and the emerging mid-range theory, their fine tuning will be an iterative process. For example, an initial proposition emerging from RBV, described in very general terms, may be that a healthcare organisation that invests in improvement may increase its improvement skill base and capability of its workforce which enables it to sustain better performance over time. As data are gathered from case to case, data analysis and integration will support CMOC testing to refine the understanding of associated mechanisms and conditions. For example, data analysis may subsequently show that investment in the form of staff development may generate additional commitment to improvement and loyalty to the organisation as a whole, whereas relying on external resources, for example consultancy, does not. This may be contingent on managers recognising the new skills of the workforce, and their ability to redeploy individuals where their skills have maximum impact around future organisational needs. This new CMOC can then be tested and further refined across other embedded units and cases, seeking disconfirming or contradictory evidence.

Practically, CMOCs will be developed using a patternmatching logic by focusing attention on 'if-then' relationships $^{29} 34$ that might be predicted by theory, are evident within the data collected from participants, or which can be abstracted across participants and cases. ${ }^{30}$ Consistent with comparative case study research, each case will be regarded as a 'whole study' in which convergent and contradictory evidence is sought and then considered across the cases. The analytical outputs will comprise:

- A conceptual framework, reflecting the context of improvement within healthcare organisations, which extends the RBV; and

- A mid-range, theory (or theories) which explain how improvement work creates strategic value for healthcare organisations, and which pays attention to the contingencies which are critical to success.

Quotations will be used to illuminate the analysis, each accompanied by detail of the case within which the data were collected, and the participant's organisational role. Inevitably, participants may provide information which directly or indirectly discloses the identity of individuals or organisations. Where this occurs, alternative 
ways of recording this information will be used, such as the use of generic role or organisational titles.

\section{ETHICS AND DISSEMINATION}

Good practice in ensuring appropriate research governance of the study, including ethical review, will be adopted. ${ }^{44}$ Regular face-to-face and virtual meetings of the study team will provide opportunities for on-going researcher supervision and critical review of study processes and outputs. As patients are not participants. Internal facilitators will advise on any specific research governance approvals that may apply.

As health organisations will be invited to participate in this study through the networks of the study team, the initial approach will be by letter, and it will be made clear that participation will be entirely voluntary. It is unlikely that any participating organisations will be in direct competition to each other, and there is little potential for commercially sensitive information to be accessed during the study. However, as a matter of course, all participating organisations will be provided with written summaries of the analysis relevant to their specific context. This will provide an opportunity to request that any such material is removed if it would not be feasible to present this in an anonymous way in study reports. There is the potential that participants will deliberately, or otherwise, highlight issues which may give cause for concern, for example unacceptable service quality or organisational practice. Should issues of this nature occur in the course of data collection, the study information provided to participants will indicate that the study team reserve the right to raise concerns with the appropriate authority if an agreed plan of action could not be established with the individual concerned. Individual participants within each organisation will be approached by a letter of invitation from the study team which, again, will establish that participation is voluntary. Potential participants will be provided with written information about the study, and will be asked to provide written indication of informed consent prior to data collection. Once consent is provided, then participants will be able to select the date and time of any data collection activity to minimise the risk of burden.

No pre-existing, formal relationships between the interviewer and participants that may compromise data collection are anticipated. To ensure anonymity, all participants will be assigned a unique identifier which will be used to organise the study record, including interview transcripts. While good practice in ensuring the quality of data collection, all participants will be routinely provided with a copy of their interview transcript, giving an additional opportunity to ensure that confidentiality and anonymity are protected.

Scientific reports of the study findings will reflect published standards for the reporting of qualitative research. ${ }^{45}$ In addition to accompanying lay reports, research outputs will include a framework for evaluating the economic impacts of quality improvement, and practical guidance for health service managers that maximises the impacts of investment in quality improvement.

\section{DISCUSSION}

The purpose of this investigation is not to judge the relative merits of different healthcare improvement programmes. Rather it is to develop novel, explanatory insights that explore the links between an organisation's internal resources and the external strategic environment within the context of improvement work. A programme theory, underpinned by RBV, provides an initial hypothesis that organisational performance can be explained through the presence of VRIN improvement resources. RBV provides an appealing explanation about why some organisations thrive and survive, however, it has yet to be applied to understanding organisational impacts of improvement. The use of RBV as a programme theory for improvement also provides new opportunities to generate qualitative insights which add to its theoretical integrity.

The influence of the organisational context on healthcare improvement endeavour is widely acknowledged, and is often considered in terms of an array of forces influencing the outcomes of improvement work, ${ }^{46}$ which may be the focus of tailoring implementation activity. ${ }^{47}$ The adoption of a realist perspective provides an opportunity to adopt a more nuanced approach to the analysis of context, for example, in understanding how different mechanisms of action generated by improvement work may play out differently within the same organisation.

RBV is one theoretical perspective which warrants attention within the field of improvement science. ${ }^{48}$ Inevitably, this perspective will dominate data collection, analysis and the interpretation of findings. The use of pattern-matching logic to be used in the integration of findings requires attention to be paid to confirmatory, complementary and contrary findings, ensuring that the investigation is open to alternative explanatory evidence. As with many applied investigations of this kind, a key source of data within this investigation is the perceptions of study participants. Inevitably choices have to be made about which participants to include. In this study, the selection of participants will not be driven by organisational roles or other personal attributes. Rather sampling will be driven by work to uncover the complex systems which characterise the organisation and conduct of improvement within organisations, and will ensure that different understandings of these systems, and VRIN resources which may be hidden in any one view, are represented within the data. Prioritising participants' first-hand experiences, rather than general attitudinal reflections, together with the use of triangulation across additional forms of data, will add strength to their interpretation within this study. Open-ended questions and a facilitative interviewing style will provide participants 
with opportunities to raise issues that are peripheral to concepts from RBV.

Adoption of a critical realist stance within the investigation reflects a particular view about the contextually contingent nature of improvement work, and consequently the nature of theory driving the investigation. $\mathrm{RBV}$ is not a contingent theory from this critical realist perspective. Indeed there are some criticisms about whether RBV is indeed a theory at all, not least in a potential tautology around novelty. However, the focus of this investigation is not to test RBV through the correlational investigation of resources and performance in healthcare organisations. Nor does it reflect the emphasis on stakeholder engagement which is a cornerstone of realist work driving the development of healthcare policy. Its purpose is to use RBV to observe and theorise about those mechanisms which may explain why and how healthcare organisations invest time and energy in improvement, and how this can add value to their organisational mission within dynamic political, social and financial contexts.

\section{Author affiliations \\ ${ }^{1}$ School of Healthcare Sciences, Bangor University, Bangor, UK \\ 2King's College London, London, UK \\ ${ }^{3}$ Public Health Wales, Cardiff, UK \\ ${ }^{4}$ Betsi Cadwaladr University Health Board, Glan Clwyd Hospital, Bodelwyddan, UK}

Contributors CRB secured funding for the study, conceived and designed the study, and drafted the manuscript. JRM contributed to the conception and design of the study, revisions of the manuscript, and has read and approved the final manuscript to be published. GR contributed to the design of the study, revisions of the manuscript, and has read and approved the final manuscript to be published. AW contributed to the design of the study, revisions of the manuscript, and has read and approved the final manuscript to be published. AH contributed to the design of the study, revisions of the manuscript, and has read and approved the final manuscript to be published.

Funding This work is supported by the Health Foundation through an Improvement Science Fellowship awarded to CB.

\section{Competing interests None.}

Ethics approval Ethical review has been provided by Bangor University Ethics Committee (4 April 2014).

Provenance and peer review Not commissioned; peer reviewed for ethical and funding approval prior to submission.

Open Access This is an Open Access article distributed in accordance with the Creative Commons Attribution Non Commercial (CC BY-NC 4.0) license, which permits others to distribute, remix, adapt, build upon this work noncommercially, and license their derivative works on different terms, provided the original work is properly cited and the use is non-commercial. See: http:// creativecommons.org/licenses/by-nc/4.0/

\section{REFERENCES}

1. Barney J. Firm resources and sustained competitive advantage. J Manag 1991;17:99-120.

2. Barney J, Clarke D. Resource based theory: creating and sustaining competitive advantage. Oxford: Oxford University Press, 2007.

3. Lockett A. Edith Penrose's legacy to the resource-based view. Manage Decis Econ 2005;26:83-98.

4. Teece DJ, Pisano G, Shuen A. Dynamic capabilities and strategic management. Strateg Manag J 1997;18:509-33.
5. Ambrosini V, Bowman C. What are dynamic capabilities and are they a useful construct in strategic management? Inter J Manag Rev 2009;11:29-49.

6. Newbert SL. Empirical research on the resource-based view of the firm: an assessment and suggestions for future research. Strat Manag J 2007;28:121-46.

7. Lockett A, Thompson S, Morgenstern U. The development of the resource-based view of the firm: a critical appraisal. Inter J Manag Rev 2009;11:9-28.

8. Kraaijenbrink J, Spender J, Groen AJ. The Resource-Based View: a review and assessment of its critiques. J Manag 2010;36:349-72.

9. Propper C. Competition, incentives and the English NHS. Health Econ 2012;21:33-40.

10. Ferlie E, Ashburner L, FitzGerald L, et al. The new public management in action. Oxford: Oxford University Press, 1996.

11. Porter ME, Teisberg EO. Redefining healthcare: creating value-based competition on results. Boston: Harvard Business School Press, 2006.

12. McCLure ML, Poulin MA, Sovie MD, et al. Magnet hospitals: attraction and retention of professional nurses. Kansas City: American Academy of Nurses, 1983.

13. Bate $P$, Mendel P, Robert G. Organizing for quality: the improvement journeys of leading hospitals in Europe and the United States. Oxford: Radcliffe Publishing Ltd, 2008.

14. Doran T, Roland M. Lessons from major initiatives to improve primary care in the United Kingdom. Health Aff 2010;29:1023-9.

15. Whittington R. What is strategy, and does it matter? London: Cengage Learning, 2001.

16. Rosner M. Economic determinants of organizational innovation. Adm Sci Q 1968;12:614-25.

17. Teece DJ. Explicating dynamic capabilities: the nature and microfoundations of (sustainable) enterprise performance. Strat Manag J 2007;28:1319-50.

18. Bierly PE, Damanpour F, Santoro MD. The application of external knowledge: organizational conditions for exploration and exploitation. J Manag Stud 2009;46:481-509.

19. Michie S, van Stralen MM, West R. The behaviour change wheel: a new method for characterising and designing behaviour change interventions. Improv Sci 2011;6:42.

20. Rycroft-Malone J, Seers K, Titchen A, et al. What counts as evidence in evidence-based practice? J Adv Nurs 2004;47:81-90.

21. Scott A, Skea J, Robinson J, et al. Designing 'interactive' environmental research for wider social relevance. Special Briefing No. 4, ESRC Global Environmental Change Programme, 1999

22. Novotny $\mathrm{H}$, Scott $\mathrm{P}$, Gibbons $\mathrm{M}$. Re-thinking science. Knowledge and the public in an age of uncertainty. Cambridge: Polity Press, 2001.

23. Greve $\mathrm{CH}$. Organisational learning from performance feedback Cambridge: Cambridge University Press, 2003.

24. Bate $P$, Robert $G$. Experience-based design: from redesigning the systems around the patient to co-designing services with the patient. Qual Saf Health Care 2006;15:307-10.

25. Checkland P. Soft systems methodology. A thirty year retrospective. Chichester: John Wiley \& Sons Ltd, 1999.

26. Dopson S, Fitzgerald L. Knowledge to action? Evidence-based health care in context. Oxford: Oxford University Press, 2005.

27. Checkland P. Systems thinking. Systems practice. Chichester: John Wiley \& Sons Ltd, 1993.

28. Kontos PC, Poland BD. Mapping new theoretical and methodological terrain for knowledge translation: contributions from critical realism and the arts. Implement Sci 2009;4:1

29. Pawson R, Tilley N. Realistic evaluation. London: Sage Publications, 1997.

30. Yin R. Case study research: design and methods. Thousand Oaks: Sage Publications, 2008.

31. Ovretveit J, Klazinga N. Learning from large-scale quality improvement through comparisons. Int J Qual Health Care 2012;24:463-9, (Advance access, published August 8th).

32. Rycroft-Malone J, Burton C. Paying attention to context in improvement research. Worldviews Evid Based Nurs 2010;7:121-2.

33. Lewin K. Defining the "field at a given time". Psychol Rev 1943;50:292-310.

34. Pawson R. The science of evaluation London: Sage Publications, 2013

35. Ovseiko P, Heitmueller A, Davies SM, et al. Improving accountability through alignment: the role of academic health science centres and networks in England. BMC Health Serv Res 2014;14:24.

36. Rycroft-Malone J, Wilkinson J, Burton C, et al. Implementing health research through academic and clinical partnerships: a realistic evaluation of the Collaborations for Leadership in Applied Health Research and Care (CLAHRC). Implement Sci 2011;6:74.

37. Mockford C, Staniszewska S, Griffiths F, et al. The impact of patient and public involvement on UK NHS health care: a systematic review. Int J Qual Health Care 2012;24:28-38. 
38. Staniszeska S, Thomas V, Seers K. Patient and public involvement in the implementation of evidence into practice. Evid Based Nurs 2013;16:97.

39. Rycroft-Malone J, Wilkinson J, Burton C, et al. Collaborative action around implementation in Collaborations for Leadership in Applied Health Research and Care: towards a programme theory. J Health Serv Res Policy 2013;18:13-26.

40. Masterson P, Burton C, Rycroft Malone J, et al. Towards a programme theory for fidelity in the evaluation of complex interventions: a process evaluation of the OTCH trial. J Eval Clin Pract 2014;20:445-52.

41. Spradley JP. Participant observation. Orlando: Harcourt Brace Jovanovich College Publishers, 1980.

42. Hsieh H, Shannon S. Three approaches to qualitative content analysis. Qual Health Res 2005;15:1277-88.

43. Maryring P. Qualitative content analysis. Forum: Qual Soc Res 2000;1:20. Retrieved 25 January 2014. http://www. qualitative-research.net/index.php/fqs/article/view/1089/2386
44. Department of Health. Research governance framework for health and social care. London: Department of Health, 2005.

45. Tong A, Sainsbury P, Craig J. Consolidated criteria for reporting qualitative research (COREQ): a 32-item checklist for interviews and focus groups. Int J Qual Health Care 2007;19:349-57.

46. Robert $\mathrm{G}$, Fulop $\mathrm{N}$. The role of context in successful improvement In: Health Foundation, eds. Perspectives on context. A selection of essays considering the role of context in successful quality improvement. London: Health Foundation, 2014:31.

47. Baker R, Camosso-Stefinovic J, Gillies C, et al. Tailored interventions to overcome identified barriers to change: effects on professional practice and health care outcomes. Cochrane Database Syst Rev 2010(3):CD005470.

48. Crilly T, Jashpara A, Trenholm S, et al. Knowledge mobilisation in healthcare organisations: synthesising evidence and theory using perspectives of organisational form, resource based view of the firm and critical theory. NIHR Service Delivery and Organisation Programme, 2013. 